\title{
La lucha simbólica por la educación en la globalización neoliberal
}

NOELIA FERNANDEZ GONZALEZ Universidad Autónoma de Madrid, Madrid, España

\section{RESUMEN}

En el paso a la postmodernidad, la globalización constituye un proceso complejo que afecta a la configuración del Estado y a las políticas educativas. Lejos de la neutralidad, esta globalización neoliberal ha contribuido a los procesos de híper acumulación de capital, provocando que el Estado se comporte como un Estado competitivo, con menos competencias y obligado a favorecer esos procesos de acumulación. Las políticas educativas tienden también a este objetivo, favoreciendo la instalación de cuasi mercados educativos, como en el caso de España, especialmente con la última ley de reforma educativa de 2013. Estas políticas son resignificas y reapropiadas por individuos y organizaciones, creando eventualmente discursos de resistencia. La educación se convierte así en espacio de disputa simbólica.

\section{PALABRAS CLAVE}

globalización; neoliberalismo; Estado; privatización; cuasi mercado. 


\section{THE SYMBOLIC STRUGGLE OVER EDUCATION IN NEO-LIBERAL GLOBALIZATION}

\section{ABSTRACT}

In the passage to postmodernity, globalization is a complex process that influences on state configuration and its education policies. Far from neutrality, this neoliberal globalization serves processes of capital hyper accumulation, making the State to act as a competitive one, with less competences and forced to foster these accumulation processes. Education policies also focus on this objective, encouraging the development of quasi markets of education, like in Spain, especially after the last education reform in 2013. These policies are resignified and reappropriated by individuals and organizations, eventually creating resistance discourses. As a result, education becomes a space of symbolic struggle.

\section{KEYWORDS}

globalization; neo-liberalism; State; privatization; quasi-market.

\section{A LUTA SIMBÓLICA PELA EDUCAÇÃO NA GLOBALIZAÇÃO NEOLIBERAL}

\section{RESUMO}

$\mathrm{Na}$ transição para a pós-modernidade, a globalização constitui um processo complexo que afeta a configuração do Estado e as políticas de educação. Longe da neutralidade, essa globalização neoliberal contribuiu para os processos de hiperacumulação de capital, fazendo com que o Estado se comporte como um Estado competitivo, com menos competências e obrigado a favorecer esses processos de acumulação. As políticas de educação também tendem a atingir esse objetivo, favorecendo a instalação de quase mercados da educação, como no caso da Espanha, em particular com a última reforma da educação de 2013. Essas políticas são ressignificadas e reapropriadas por indivíduos e organizações, eventualmente criando discursos de resistência. Dessa forma, a educação converte-se em espaço de luta simbólica.

PALAVRAS-CHAVE

globalização; neoliberalismo; Estado; privatização; quase mercado. 


\section{INTRODUCCIÓN}

Sostuvo Cerny ya en 1997 que la globalización no era otra cosa que el paso de un Estado keynesiano de bienestar a un Estado competitivo, un nuevo Estado que se comporta como una "cuasi asociación empresarial" y que actúa en nombre de la competitividad. Organizaciones internacionales y supranacionales constituyen actores clave de esta globalización; condicionan fuertemente los márgenes de autonomía de los Estados e imprimen una concreta direccionalidad a sus políticas (Tarabini y Bonal, 2011). Se confirma así un encaje pleno entre la "ideología de la globalización", propugnada por estas organizaciones - basada en la competitividad y el desarrollo - (Rizvi y Lingard, 2013), y la hoja de ruta del Estado competitivo. Lejos, por lo tanto, de toda neutralidad, esta globalización ya ha sido observada como una globalización neoliberal (Díaz-Villa, 2011; Fraser, 2003; Janoschka, 2011); si "el mundo social puede ser dicho y construido de diferentes modos según diferentes principios de visión y división" (Bourdieu, 2000, p. 135), el entramado ideológico-discursivo del neoliberalismo se encarga de decir - y en ese decir, construir - un mundo que necesita de las reformas que él mismo propugna.

Este proceso de globalización, patrocinado por los organismos internacionales, genera una fuerte presión sobre los Estados nacionales para que alineen sus mandatos educativos con los principios de competitividad y eficiencia. Lo mismo sucede con la gobernabilidad, es decir, con los procesos de gestión que implementa el Estado para hacer efectivo ese mandato (Dale, 1989). En este sentido, la instalación de cuasi mercados en la educación sería la estrategia de gobernabilidad empleada por el Estado competitivo en el nuevo escenario de globalización neoliberal.

Existen múltiples definiciones de cuasi mercado y todas ellas giran en torno a la introducción en la organización educativa de, al menos, un rasgo significativo del mercado, como pueda ser la competitividad (Pérez y Salinas, 1999). Esta incorporación en la gestión pública de procedimientos e ideas propias del sector privado es lo que se ha denominado "privatización endógena" (Ball y Youdell, 2009). Dispositivos como la elección de centro, el cheque escolar o los sistemas de gestión de resultados son asociados a los cuasi mercados y constituyen algunas de estrategias de privatización endógena (Luengo y Saura, 2012; Puelles, 2005; Whitty, Power y Halpin, 1999).

Diversas políticas educativas estatales y autonómicas del Partido Popular (PP) y del Partido Socialista Obrero Español (PSOE) que parecen encajar en el ideario neoliberal, asumen rasgos de los denominados cuasi mercados (Díez-Gutiérrez, 2010; Merchán, 2012; Puelles, 2005). Con frecuencia, estas políticas son percibidas como transformaciones virulentas que, consecuentemente, generan discursos de resistencia que deben ser analizados como "expresiones de identidad y ciudadanía” (Janoschka, 2011, p. 126). Dentro de este marco de situación, merece especial interés la última reforma estatal, la Ley Orgánica para la Mejora de la Calidad Educativa (LOMCE), fuertemente criticada por algunos sectores académicos y sociales (Bernal y Lorenzo, 2012; Bolívar, 2013; Escudero, 2013; Monarca, 2012b; Monarca, Fernández-González e Sandoval, 2015). A este respecto, las movilizaciones sociales, especialmente la marea verde, constituyen esas 
expresiones de identidad y de ciudadanía surgidas para defender derechos sociales que perciben en riesgo de erosión (Díez-Gutiérrez y Guamán, 2013). Con mayor o menor grado de consciencia sobre la parcialidad de toda decisión política, los sujetos y los grupos resignifican siempre las políticas (Ramírez, 2010). En algunos casos generan claros discursos de resistencia. En otros, sin embargo, remodelan sus representaciones y prácticas educativas para adaptarse de maneras diversas (Ball, 2003; Luengo y Saura, 2012).

Tal como se ha sostenido, el proceso de globalización ha traído intensos cambios en la configuración de los Estados nacionales. Pero también está promoviendo transformaciones a nivel social, cultural y, en lo que aquí interesa, educativo. En línea con lo que sugieren diversos autores, estos cambios han tenido fuertes consecuencias en la configuración de las identidades de los sujetos y de las instituciones conformadas bajo la modernidad (Ball, 2013; Bauman, 2005; Dubet, 2007). En la era postmoderna se ha impuesto una cultura de performatividad que trae necesidades de competitividad y mercantilización de la educación, y que provoca nuevas fabricaciones: "selecciones dentro de varias posibles de representaciones o versiones - de la organización o de la persona”(Ball, 2013, p. 107).

\section{POSTMODERNIDAD, GLOBALIZACIÓN Y NEOLIBERALISMO}

En su trabajo sobre la postmodernidad, Lyotard (1987) la cataloga como el fin de las metanarrativas, apuntando, sin embargo, a una paradójica situación en donde la eficiencia se convierte en la nueva deidad a la que adorar. Ciertamente existen argumentos a favor de la eficiencia, vinculados a la necesidad de que el Estado sea eficaz en sus políticas y haga una gestión responsable de los recursos públicos en la provisión de los servicios sociales (Avellaneda, 2011). Esta autora liga tales ideas al modo en que se legitima el Estado de bienestar como garante de los derechos sociales. En una situación así, la legitimidad política se relaciona con la eficiencia, pero también con la equidad o la legalidad. La cuestión torna crítica cuando, como se ha señalado, la eficiencia se erige como la nueva metanarrativa, en sustitución de las anteriores y en detrimento de todos los demás valores; es decir, cuando se convierte en el mandato del Estado, permitiendo hablar de un Estado competitivo (Cerny, 1997).

El paso a la postmodernidad ubica a la educación en una encrucijada, relacionada con dos aspectos nucleares: la situación del conocimiento y la situación del Estado en el proceso de globalización. Sobre el primer elemento, la crisis de legitimación científica (la crisis del modelo newtoniano asociado a la modernidad) supone un reto para el contenido mismo de la enseñanza (Dubet, 2007; Hargreaves, 1996). Este relativismo epistemológico de la postmodernidad sirve de caldo de cultivo para que la escuela se centre en un elemento que es cada vez más cierto: un mercado laboral crecientemente competitivo. En palabras de Dubet (2007, p. 52), "la institución [escolar] fundamenta menos su legitimidad sobre sus valores que sobre su utilidad".

El segundo aspecto de la encrucijada, estrechamente vinculado con el anterior, es la crisis de legitimidad del nuevo Estado. Como explican Tarabini y Bonal 
(2011) utilizando las categorías de Roger Dale (1989), el Estado competitivo tiene por objetivo contribuir a los procesos de acumulación de capital, lo que implica la erosión de los derechos sociales, la educación entre ellos, y por lo tanto, dificulta la legitimación del Estado frente a su ciudadanía al no mantener un contexto adecuado para su reproducción. Esto remodela el mandato de los sistemas educativos, que deben tender también a la mayor competitividad. Del mismo modo que el Estado competitivo entra en contradicción con los valores del Estado de bienestar; los sistemas educativos modelados en el Estado de bienestar e inspirados por sus principios entran en contradicción con la nueva realidad social, de tal suerte que nos enfrentamos a

un sistema educativo que pretende ser inclusivo en una sociedad capitalista, competitiva, de mercado, neoliberal; que necesita diferenciar y transformar en mercancía los títulos académicos, en donde la abundancia de los mismos es un problema evidente para aquellos que buscan la diferenciación a través de ellos. (Monarca, 2012b, p. 109)

A este respecto, cabe recordar que el Estado de bienestar no es solo el resultado de sucesivas luchas sociales por la consecución de derechos; sino también una necesidad histórica del sistema capitalista que, de lo contrario, habría muerto por inanición. Unida al Estado de bienestar, nace la organización social fordista con el objetivo de fomentar el consumo interno y así favorecer el propio enriquecimiento; apoyándose siempre sobre la explotación del tercer mundo, una constante durante todo el siglo XX (Fraser, 2003).

Una contradicción de dimensiones más amplias que la enfrenta el Estado de bienestar al Estado competitivo, aunque muy vinculada a ésta, es la que cuestiona la necesidad del Estado en el nuevo escenario de globalización. De igual manera que los principios de la modernidad han erosionado el programa institucional de la escuela; el avance del capitalismo en la nueva era postmoderna ha cuestionado el marco nacional que inicialmente sirvió a los objetivos del capital. Es decir, si previamente se han referido aquí las dificultades del proceso de legitimación del Estado frente a su ciudadanía, ahora se trata de las dificultades del proceso de legitimación del Estado frente al sistema capitalista globalizado (Dubet, 2007; Fraser, 2003).

David Harvey (1990) ubica a la globalización en el seno del paso a la postmodernidad y la caracteriza principalmente por sus efectos para la economía mundial. El autor la vincula a la comprensión espacio-temporal y a la acumulación flexible, elementos que han dado lugar a unas comunicaciones y finanzas globalizadas que han servido al mayor provecho de los procesos de híper acumulación en el capitalismo tardío. Cabe hablar ahora de una organización social postfordista. En este escenario, las organizaciones internacionales son actores clave que han propiciado esos procesos de híper acumulación haciendo propaganda, defensa y promoción de una "ideología de la globalización”, encabezada por los valores del "desarrollo" y la “competitividad" (Rizvi y Lingard, 2013). Es por esto que Chomsky y Dieterich (1996) no dudan en hablar de un "proto Estado capitalista global" formado por estas organizaciones internacionales - el Fondo Monetario Internacional (FMI), 
el Banco Mundial (BM), la Organización para la Cooperación y el Desarrollo Económico (OCDE) y la Organización Mundial del Comercio (OMC), entre otros.

Este proto Estado capitalista presiona a los Estados para que transiten hacia el Estado competitivo, limitando su capacidad, es decir, su margen de autonomía (Dale, 1989; Tarabini y Bonal, 2011). De esta manera, el sistema capitalista sortea la contradicción con el marco nacional. Asistimos así a un vaciamiento de las competencias del Estado, tanto hacia arriba (hacia organizaciones supracionales) como hacia abajo (descentralización regional de competencias). Desde esta lógica trabaja, por ejemplo, el principio de subsidiariedad de la Unión Europea. Pero esta descentralización de competencias, lejos de ser una cuestión aséptica y meramente técnica, se cruza con diversos mecanismos de mercados. Así lo percibieron Whitty, Power y Halpin (1999), cuando su estudio sobre las tendencias de descentralización educativa se convirtió inevitablemente en un estudio sobre la instalación de cuasi mercados educativos. Se trata, en fin, de un sistema de gubernamentalidad multinivel que confía en el laissez faire y que está atravesado por mecanismos de mercado diversos y distribuidos de modo difuso (Fraser, 2003). En su rol de proto Estado mundial y, amparadas en las nuevas competencias que asumen (a veces de manera jurídica, como en caso de la Unión Europea; a veces a través de su poder suave, como en el caso de la OCDE); estas organizaciones determinan la direccionalidad de las políticas educativas en distintos lugares del mundo y a través de mecanismos dispares en función de las diferencias contextuales (Tarabini y Bonal, 2011). En este punto, la literatura es casi unánime sobre el impacto de las organizaciones internacionales en el diseño de las políticas educativas (Pedró, 2012; Pini, 2010; Pongratz, 2013). Lejos, sin embargo, de cualquier democracia internacional, el funcionamiento de las organizaciones internacionales que componen el proto Estado mundial capitalista se comprende cuando se conoce el poder real de cada Estado nacional: es una cuestión de realpolitik (Chomsky y Dieterich, 1996).

Dentro de la nueva arquitectura global post-keynesiana, los Estados del Primer Mundo tienen una relación simbiótica con sus grandes capitales transnacionales (Chomsky y Dieterich, 1996). Dejando al margen la cuestión de si España es un país primermundista o una semiperiferia; la identificación del gobierno español con los intereses de las transnacionales españolas es una tesis avalada por la realidad. Apórtense dos ejemplos. El primero de ellos es el aval del Estado de España a la empresa Sacyr para su contrato de ampliación del canal de Panamá y el papel mediador de la ministra de Fomento, Ana Pastor, durante la crisis por sobrecostes en 2014. El segundo ejemplo, es la intervención de la diputada del Grupo Popular, Maria Aránzazu Miguélez Pariente, el día 6 de mayo en el Pleno del Congreso de los diputados. Durante la sesión, la diputada defendió los beneficios económicos del Transatlantic Trade and Investment Partnership (TTIP) para España con las siguientes palabras:

[...] nosotros creemos en la capacidad de las empresas españolas, que están construyendo el metro de Lima o la nueva terminal del aeropuerto de Heathrow, y vamos a hacer lo que esté en nuestras manos para que el acuerdo se firme cuanto antes porque creemos que es bueno para España. (Cortes Generales de España, 2014) 
La diputada identifica en sus palabras los intereses económicos de España con los intereses económicos de Ferrovial, encargada de la ampliación del aeropuerto Heathrow; y Actividades de Construcción y Servicios (ACS) y Fomento de Construcciones y Contratas (FCC), quienes llevarán a cabo las obras del metro de Lima. Considerando, sin embargo, la presencia de estas empresas en paraísos fiscales para reducir el pago de impuestos en España (Basterra, 2011); esa identificación es más que dudosa. ${ }^{1}$ Corporaciones transnacionales, como las recién mencionadas, son otro elemento nuclear para comprender el proceso de globalización. A este respecto, la participación cercana de estas corporaciones en las negociaciones de los organismos internacionales y supranacionales (Hernández, 2013) es otro argumento más para defender la simbiosis de las transnacionales, no sólo con los Estados primermundistas, sino también con el proto Estado mundial capitalista.

Ante esta arquitectura global, cobra firmeza la tesis de Cerny (1997), según la cual la globalización no es otra cosa que el paso de un Estado keynesiano a un Estado competitivo que se comporta como una "cuasi organización empresarial" que participa en el mercado mundial. Siendo esto así, los Estados trabajan en favor de los intereses de estas transnacionales a través, por ejemplo, de la firma de tratados internacionales de libre comercio que, en la práctica, significan la independencia de estas corporaciones de los Estados nacionales. La participación de los Estados en este tipo de acuerdos internacionales, unida a su vaciamiento de competencias a través de organizaciones supranacionales e internacionales, y las políticas de recorte en gasto social (necesarias para alcanzar el mandato de acumulación de capital) son elementos que limitan la capacidad del Estado, presionándolo para actuar como un Estado competitivo.

La globalización se asocia casi simbióticamente a una representación concreta de sí misma hecha por el entramado ideológico-discursivo del neoliberalismo. El discurso neoliberal cosifica la globalización como un cambio inevitable e inminente (Fairclough, 2000; Rizvi y Lingard, 2013), del mismo modo que representa como inevitables las repetidas crisis económicas (Chosmky y Dieterich, 1996). Se trata de una representación de la realidad pensada y creada para ocultar las acciones de los actores político - económicos que están detrás del proceso de globalización y que se benefician de él. A modo de ejemplo, David Harvey (2004a) desentraña el papel de los fondos especulativos de cobertura respaldados por las políticas del FMI en la crisis asiática de 1997. Desde esta premisa, muchos autores no dudan en catalogar a esta globalización como una "globalización neoliberal" (Díaz-Villa, 2011; Fraser, 2003; Janoschka, 2011). "Globalización” y "neoliberalismo", explica Díaz-Villa (2011), constituyen significantes articulados: la globalización viene ligada a un individualismo consumista, al dar acceso a los individuos a un mercado global; y el neoliberalismo pretende la retirada del Estado en las áreas de servicios sociales para que los agentes privados las provean. En su estudio sobre la postmodernidad, también Lyotard (1987) anticipaba el consumo individualista como uno de los rasgos

1 Datos como estos denuncia Marta Sibina, editora de la revista Cafèambllet, en el vídeo accesible en: <https://www.youtube.com/watch?v=blRKSaXexb0>. En las elecciones generales de 20 de diciembre de 2015 al Congreso español, Sibina se presentó por primera vez como diputada por la lista de Barcelona en Comú, obteniendo el escaño. 
propios de la nueva era. La ideología de la privatización, es decir, la fe en el mejor funcionamiento de lo privado (Rizvi y Lingard, 2013) sería otro aspecto clave del entramado neoliberal, levantado sobre el fundamento del laissez faire.

El discurso neoliberal de la globalización, donde el libre mercado constituye la vía de desarrollo ha sido ampliamente contestado. En primer lugar, cabe mencionar el movimiento antiglobalización o altermundista, que cobró visibilidad a raíz de las movilizaciones de Seattle en rechazo a la cumbre de la OMC, y dos años más tarde en Génova, en la contra-cumbre del G8. Estos encuentros daban cita a plataformas, grupos y sindicatos, que parecían compartir la lucha contra el capitalismo global, reconociendo a los actores internacionales y supranacionales como los grandes valedores del proyecto neoliberal. Estos grupos y estas luchas denuncian la mercantilización de cada vez más áreas y sectores, desde recursos naturales como el agua y las tierras comunales, hasta sectores sociales como la educación y la sanidad, pasando por los recursos intangibles, como la cultura o la información. En opinión de Laval y Dardot (2015, p. 109), lo que caracteriza a estas luchas anticapitalistas es que comparten la idea de lo "común" como "bandera de la movilización, consigna de la resistencia, hilo director de la alternativa". Cabe mencionar otras muchas luchas concretas en distintos lugares del mundo: el alzamiento zapatista en rechazo del Tratado NAFTA en 1994, las guerras del agua en Cochabamba a finales del siglo pasado, las ocupaciones de 2003 protagonizadas por mujeres en la plataforma de Chevron oil en la bahía del río Escravos (Nigeria) para evitar expropiaciones en su entorno, las ocupaciones de campesinos españoles en tierras de Somonte en 2012... Dentro del relato que denuncia y rechaza esta globalización neoliberal, cada una de estas batallas es interpretada como una pieza de una misma lucha.

Como bien explica David Harvey (2004a), lo que caracteriza a estas luchas es el contenido sustantivo de sus reivindicaciones. En décadas anteriores, era el movimiento sindicalista tradicional quien protagonizaba la lucha, articulando sus reivindicaciones en el campo de la reproducción ampliada, es decir, ubicando su lucha en el centro de trabajo. Sin embargo, las luchas que aquí se mencionan denuncian las dinámicas de acumulación por desposesión que desarrolla el capitalismo global para abrir nuevas áreas al mercado, áreas que antes le estaban cerradas, como la educación. En opinión del geógrafo marxista queda pendiente buscar puntos de confluencia entre ambas luchas ya que, de la misma manera que los movimientos tradicionales prestaron poca atención a las dinámicas de acumulación por desposesión, se corre el riesgo de que las nuevas luchas obvien lo que pasa en el centro del capitalismo, es decir, en los lugares de producción de la plusvalía, donde el trabajo temporal y precario es cada vez más frecuente.

\section{UN RÉGIMEN DE PERFORMATIVIDAD}

En este escenario, el concepto de performatividad, nos permite comprender la realidad educativa. La idea de performatividad denota el poder de hacer cosas con palabras. En los sesenta, el lingüista John L. Austin (1971) fue el primero en descubrir los enunciados realizativos o performativos: aquellos que construyen realidad social con ser pronunciados, por ejemplo, las fórmulas concretas para 
contraer matrimonio o para prestar juramento. Íñiguez (2003) explica cómo surge la teoría de los actos del habla a raíz de este descubrimiento. Esta teoría sostiene que, por el mero hecho de hablar, de expresarse, los sujetos llevan a cabo un acto como consecuencia de los efectos que causan sus palabras al crear imágenes sociomentales en los destinatarios de esos mensajes. Partiendo, de la noción sencilla de que la performatividad es el poder de hacer cosas con palabras, interesan aquí tres aspectos para mirar y comprender la realidad educativa:

1. El papel de los medios de comunicación en la representación del mundo social,

2. La unión entre riqueza y conocimiento $y$

3. El empleo de tecnologías de poder para reorientar la educación.

Dentro la arquitectura global esbozada más arriba, los medios de comunicación, mayoritariamente controlados por grandes transnacionales, juegan un papel clave en la fabricación de la opinión pública (Una mosca en..., 2014; Herman y Chomsky, 2002). Constituyen mecanismos para crear una imagen negativa y una explicación simplista de la realidad en ciertos lugares el mundo, como Venezuela, Cuba o Corea del Norte; por lo general lugares donde se discute, se cuestiona o se niega el libre mercado como vía de desarrollo. Estas representaciones de la realidad sirven para ocultar el comportamiento real de los Estados burgueses para mantener su hegemonía (véase el caso de la contra en Nicaragua, en Chomsky, 2007). El objetivo último es eliminar la posibilidad de pensamiento alternativo al interior de los Estados. En términos gramscianos, los medios de comunicación sirven para construir hegemonía. Esto sirve en gran medida para construir los habitus de los ciudadanos, es decir, las estructuras cognitivas a través de las que aprehenden el mundo (Bourdieu, 2000). Este rol de los medios de comunicación en la fabricación de opinión es un argumento más para sostener que la globalización no es sólo un fenómeno económico, sino también cultural y político (Tarabini y Bonal, 2011).

El segundo aspecto que aquí interesa es la unión entre ciencia y riqueza. La primera revolución industrial supuso el descubrimiento de que "no hay técnica sin riqueza, ni riqueza sin técnica" (Lyotard, 1987, p. 37). De esta manera la ciencia se convierte también en una fuerza de producción. El capital se interesa por la inversión en ciencia porque la ciencia permite mejorar su tecnología y lograr una mejor relación input/ouput, es decir, lograr mayor eficiencia. Esto trae dos consecuencias directas. La primera es que solo desde la riqueza hay acceso al saber. La segunda es que el saber queda instrumentalizado al servicio del enriquecimiento. A la postre, ocurre que ciertas áreas o líneas de investigación cuentan con más apoyos en función de su contribución a la acumulación de capital. Los investigadores cuyos trabajos no son útiles en este sentido, es decir, los "violadores de tabúes" (Chomsky y Dieterich, 1996), sufren la exclusión de foros públicos o la obstaculización a becas de investigación. Se concluye, en fin, que la eficiencia es el valor legitimador no solo de la decisión política, sino también del conocimiento científico. Sin embargo nada es eficiente en sí mismo; la eficiencia, para existir, debe ser constatada, lo que exige encontrar maneras de medir la relación inputloutput. Ya no solo importa ser eficiente, sino probar y garantizar esa eficiencia. Es por esto que se ordena "sed operativos, es 
decir, conmensurables, o desapareced" (Lyotard, 1987, p. 5). La inversión necesaria para administrar una prueba de eficiencia se convierte en la cuestión crítica. Se trata de una disputa donde ganará el actor que encuentre más espacios conmensurables, no necesariamente el más eficiente. Por esto, la nueva sociedad postmoderna es más una sociedad de control (Deleuze, 2006) que una sociedad disciplinaria - como catalogó Foucault a la organización fordista (Fraser, 2003) - . Ahora es necesario conocer y medir la actividad productiva de los actores, porque todo lo que no se mida, simplemente no existe.

Esta sociedad de control, donde lo importante es la medida de productividad, es denominada por Stephen Ball una "sociedad performativa" o "cultura performativa" $(2003,2013)$. Utilizando la obra de Lyotard, Ball toma el concepto de performatividad para aplicarlo a la sociología educativa. Aplica también categorías foucaultianas para comprender el surgimiento de nuevos mecanismos de poder que afectan a la identidad del individuo y de la organización. Explica Ball que esta sociedad performativa es "una tecnología, una cultura, una modalidad de reglamentación que utiliza evaluaciones, comparaciones e indicadores como medios para controlar, desgastar y producir el cambio" (Ball, 2003, p. 89). Estas tecnologías de poder prefiguran una imagen del profesionalismo del docente, del nuevo currículum educativo, del funcionamiento del centro... en fin, una imagen de la calidad de la educación, a la que deben tender todos los sujetos. En este sentido, los individuos y las organizaciones, para legitimar su actividad buscan modos de adaptarse a esas imágenes y así surgen las fabricaciones: "selecciones dentro de varias posibles de representaciones - o versiones - de la organización o de la persona" (Ball,2013, p. 107). En ocasiones, estas imágenes se alcanzan a través de actos falsos; argucias y triquiñuelas para generar la apariencia legitimadora, tanto en términos de productividad como en términos de marketing.

Justamente porque, como más arriba se ha sostenido, en la lucha por la legitimidad, vencerá el actor que logre abrir más espacios de conmensurabilidad, el poder en esta sociedad performativa es una cuestión de abrir espacios de medida: asistimos a una lucha por la perceptibilidad (Ball, 2003). De resultas de esta disputa, la actividad humana puesta en valor se va reduciendo a todo lo que se pueda medir, limitando el pensamiento a cálculos entre costes y beneficios: "ya no nos permitiremos emplear como instrumentos de nuestro pensamiento conceptos que no podemos describir en términos de operaciones" (Bridgman apud Marcuse, 1993, p. 43).

La prueba Programme for International Student Assessment (PISA) constituye el ejemplo paradigmático que ilustra este régimen de performatividad. La centralidad de PISA en el panorama internacional de la política educativa comparada es incuestionable: numerosos países han acometido reformas en sus sistemas educativos a raíz de los resultados obtenidos (Pedró, 2012; Pereyra, Luzón y Torres, 2010; Pongratz, 2013; Tröhler, 2009). El protagonismo es tal que la OCDE ha llegado a ser catalogada como una suerte de ministro Mundial de Educación (Kamens, 2013, p. 123 apud Conferencia PISA, 2 de septiembre de 2011).

Sobre el primer aspecto de la sociedad performativa, el impacto de PISA en la prensa a nivel mundial es ya incuestionable, creando incluso shocks nacionales, como el caso de Alemania a raíz de PISA 2000 (Pongratz, 2013). Sobre este aspecto, 
algunos autores han destacado la representación negativa de la realidad educativa que hace la prueba PISA (Bolívar, 2010; Pedró, 2012). Justamente, la negatividad es una de las características propias de la sociedad performativa (Ball, 2003). La fotografía negativa del presenta justifica la necesidad del cambio que la misma prueba induce.

En segundo lugar, esta prueba ejemplifica la lucha por la perceptibilidad. Efectivamente, PISA ha tenido éxito en la apertura de espacios conmensurables. La OCDE ha logrado presentar a su evaluación como "la medida más legítima y exacta del rendimiento educativo comparativo nacional" (Rizvi y Lingard, 2013, p. 171). De igual manera, ilustra la relación entre riqueza y ciencia. En este sentido, no se puede obviar quién es la OCDE, una organización con intereses fundamentalmente económicos que forma parte del proto Estado mundial capitalista. $\mathrm{Su}$ preocupación por la educación se fundamenta en la importancia que, desde teorías del capital humano, dan a la educación como fuente de riqueza nacional (Gurría, 2011). Ya desde su nacimiento, la OCDE se interesó por la educación: su primera conferencia, celebrada en 1961 en Washington, llevaba por nombre Policy Conference on Economic Growth and Investment in Education (Conferencia sobre Políticas de Crecimiento Económico e Inversión en Educación). Desde este enfoque teórico, la educación se orienta a la mayor competitividad de las naciones, lo que encaja con el mandato educativo del Estado de favorecer los procesos de acumulación (Dale, 1989).

$\mathrm{Si}$ bien es cierto que no existe ninguna ciencia libre de valores, en este caso la legitimidad de este discurso se apoya en la neutralidad que se arroga en tanto ciencia. La OCDE ha logrado construir una imagen de PISA como elemento aséptico, vacío de ideología. Y en esa imagen de neutralidad legitima su valor como ciencia neutral. Esta característica es la que Bourdieu atribuía el 1998 al discurso del neoliberalismo al catalogarlo como un programa científico convertido en programa político, un discurso fuerte que se retroalimenta y que extrae su fuerza de la riqueza de los actores a quienes representa (los grandes capitales del mundo económico). Este poder performativo del discurso de PISA, una muestra del poder performativo del discurso neoliberal, dota a la OCDE de un gran poder simbólico - utilizando términos bourdianos - que provoca la aceptación y legitimación de su representación del mundo educativo.

El trabajo de Luis Miguel Carvalho (2009) sobre PISA ilustra todas estas ideas. Caracteriza a la prueba como un instrumento de "política tecnológica", un conjunto de conocimientos para la política que entreteje estrategias técnicas (medir, evaluar...) y sociales (representación ante la opinión pública) para crear un sentido común sobre la realidad educativa, convirtiéndose así en una herramienta de regulación. Constituye un intento por monopolizar la competencia de construir ese sentido común. A este respecto, el impacto que trianualmente despiertan los resultados de la evaluación es incuestionable (Luzón y Torres, 2013; Pedró, 2012). Pero interesa muy especialmente la construcción que hace PISA de un "discurso de la calidad educativa”, y que se vincula con la finalidad de la educación. A modo de ejemplo, la evaluación, no por materias, sino por competencias constituye una de las novedades que PISA incorpora y quizá explique su exitosa expansión global. Esta elección, sin embargo, prefigura una imagen concreta de la calidad educativa. 
El programa PISA colabora "en la fabricación de las personas para una sociedad global imaginada” (Carvalho, 2009,p.1.018). Induce a la creencia de que los jóvenes no están lo suficientemente preparados para este mundo competitivo, lo que justifica la inclusión del discurso de las competencias en los sistemas nacionales a través de, por ejemplo, evaluaciones estandarizadas (Luengo y Saura, 2012). Se trata, en fin, de una tecnología de poder que sirve para inducir el cambio deseado.

\section{LA IDEOLOGÍA DE LA PRIVATIZACIÓN}

Se ha mencionado previamente la ideología de la privatización como uno de los rasgos más significativos del entramado ideológico-discursivo del neoliberalismo. Desde la creencia del mejor funcionamiento de lo privado, el neoliberalismo significa la prosecución de un Estado mínimo. Así, en educación, la tradición thatcherista apostaba por la privatización para contribuir al "adelgazamiento" del Estado (Puelles, 2005). No obstante, esta creencia de la mejor gestión de lo privado no se agota en la estela del thatcherismo. La tercera vía, propuesta por Anthony Giddens (1999) como una alternativa para la socialdemocracia y popularizada a finales de los noventa por el gobierno laborista de Tony Blair, se articula en torno a la idea central de gestionar lo público con principios de lo privado. Es en el marco de este nuevo discurso, también denominado Nueva Gestión Pública (NGP) o en inglés, Nerw Public Management (NPM), donde la idea de los cuasi mercados encuentra su razón de ser, instalándose a través de estrategias de privatización endógena.

Las dinámicas de privatización exógena (apertura de los servicios públicos a la participación de agentes privados) son las más conocidas y clásicamente empleadas por el thatcherismo. Por su parte, las dinámicas endógenas suponen "la importación de ideas, métodos y prácticas del sector privado a fin de hacer que el sector público sea cada vez más como una empresa crecientemente comercial" (Ball y Youdell, 2009, p. 56). Investigaciones recientes indagan sobre la instalación de cuasi mercados educativos en España a través de dinámicas de privatización endógena. En esta línea, destaca el Proyecto de Investigación: “Dinámicas de privatización exógenas y endógenas en y de la educación: la implantación del modelo de cuasimercado en España”, financiado por el Ministerio de Educación a través del Plan Nacional I+D (Ref. EDU 2010/20853).

Si el Estado competitivo tiene como mandato educativo la prosecución de competitividad y eficiencia para favorecer los procesos de acumulación, cabe sostener que imprimir esa orientación a las políticas educativas, supone dar el primer paso hacia las dinámicas de privatización endógena, en tanto trae ya los primeros objetivos propios de la producción capitalista a la organización de lo público. A este respecto, cuando el escenario global es propicio al ideario neoliberal, y las organizaciones internacionales y supranacionales convierten en hegemónico ese discurso, la capacidad - en los términos que Dale (1989) la define - de mantener el mandato que el Estado de bienestar perseguía, queda muy cercenada. En otras palabras, el entorno geopolítico global limita las posibilidades de los Estados para no actuar como un Estado competitivo.

Dentro de la agenda educativa de la tercera vía, es interesante hablar de los modos de regulación postburocráticos (Bolívar, 2010). Este modelo de regulación 
se presenta como una alternativa al centralismo burocrático y se articula en torno al tándem autonomía/rendición de cuentas. Como explica este autor, se trata de establecer una suerte de "contrato" entre los centros escolares y la administración. A través de este "contrato", los centros gozan de mayor autonomía, vinculada a la rendición de cuentas y a la evaluación. Para este autor, la regulación postburocrática es un dispositivo idóneo para dinamizar las escuelas y mejorar su eficacia. Los detractores, sin embargo, de estos dispositivos, los observan como mecanismos de privatización endógena que afectan sobre el profesionalismo del docente y el currículum escolar, orientando la educación hacia una cultura performativa (Ball, 2003; Luengo y Saura, 2012, 2013).

Para observar la regulación postburocrática como mecanismos de privatización endógena, es importante destacar la estrecha unión entre el gerencialismo y cultura de la performatividad (Ball, 2003). El gerencialismo apuesta por una organización de la escuela afín a la empresa, de tal modo que se adopta una

estructura piramidal en la que el papel de los profesores, alumnos, padres y madres, se limita al de terminales más o menos ciegas en la ejecución del plan de la dirección que, a su vez, responde a los planes de la administración. (Merchán, 2012, p. 17)

De manera que, en los hechos, la autonomía del centro escolar viene unida a una organización jerárquica que fortalece la figura del director, cuyo rol es más similar al de un gerente empresarial. Esto afecta a la autonomía del profesor y a su profesionalismo. En un primer nivel, choca con su estatus de funcionario y afecta a sus derechos laborales. Así lo advierte Bolívar (2010, p. 16), quien asume de buen grado que "los equipos directivos puedan intervenir en el profesorado que accede al centro y en las necesidades de contratación". En un segundo nivel, esta organización afecta sobre su profesionalismo, limitando su autonomía. Dentro del gerencialismo, el profesionalismo del docente se llena de un significado concreto, el de conseguir los objetivos de eficacia prefijados por el director, limitándose así a una medida de rendimiento o desempeño controlada a través de evaluaciones y otros mecanismos de rendición de cuentas. Estas descripciones del profesionalismo docente obligarían a crear fabricaciones individuales y organizacionales acordes (Ball, 2013).

La regulación postburocrática se articula a través de evaluaciones y mecanismos de rendición de cuentas. Ambos dos son dispositivos diferentes que no deben confundirse. Mientras las evaluaciones constituyen pruebas para medir los aprendizajes de los estudiantes, la rendición de cuentas es un concepto más difuso. Las evaluaciones estandarizadas han sido objeto de muchas críticas: porque constituyen mecanismos para trasladar la responsabilidad a centros y profesores (Hargreaves, 1996), por su dudosa capacidad para contribuir a la mejora de la calidad y la equidad (Monarca, 2012a), por el riesgo de enseñar para el test (Barrenechea, 2010) o porque sirven como medio para la imposición de las disciplinas hegemónicas que interesan al mercado (Luengo y Saura, 2012). Todos estos argumentos permiten entender los sistemas de evaluación como un elemento clave de los cuasimercados de la educación (Monarca, Fernández-González e Sandoval, 2015). Otras postu- 
ras favorables a estas evaluaciones, las observan como dispositivos para garantizar la equidad de conocimientos en todo el territorio (Bolívar, 2010) y para inspirar políticas más eficientes (OCDE, 2013).

La noción de rendición de cuentas (accountability) debe vincularse a la necesidad de que la educación ofrezca una "garantía de calidad", concepto traído del ámbito técnico empresarial. A diferencia de las evaluaciones, que centran su atención en los resultados de aprendizaje, la idea de "garantía de calidad" se refiere más a los procesos que a los resultados. En el ámbito empresarial da lugar a la creación de sistemas para monitorear y controlar que los procedimientos de producción sigan una serie de requisitos y sean fiscalizables. Estos sistemas de monitoreo se corresponden con el paso de una sociedad disciplinaria, donde las organizaciones se caracterizaban por el dominio de los espacios y los tiempos; al paso a una sociedad de control (Deleuze, 2006), donde sujetos e instituciones se auto modelan para alcanzar los requisitos de la performatividad. El objetivo de estos sistemas de calidad en el ámbito empresarial es generar confianza en los consumidores (Charlton, 2002). Como sostiene este autor, el discurso de la rendición de cuentas constituye también una tecnología propia del gerencialismo que se introduce en la educación con el objetivo de controlar y orientar el comportamiento los individuos. Algunos autores han escrito sobre las inconveniencias de aplicar sistemas de garantía de calidad a la educación (Díaz-Palacios, 2013).

Esta introducción de conceptos propios del sector privado en la gestión de lo público cristaliza en el plano discursivo a través de estrategias concretas de "recontextualización", propias del lenguaje en el nuevo capitalismo (Fairclough, 2000). Este autor inglés explica la recontextualización como el empleo de un vocabulario propio de la gestión privada para referirse a dominios de lo público, como pueda ser la educación. A la postre se consigue que una práctica colonice de la otra, de tal modo que los cambios no quedan meramente en los discursos, sino que también reconfiguran las prácticas.

\section{EL MODELO DE CUASI MERCADO COMO ESTRATEGIA DE GOBERNABILIDAD}

La noción de "cuasi mercado" refiere los "intentos de introducir las fuerzas de mercado y las formas de decisión propias el sector privado en la provisión de la educación y de los servicios de bienestar" (Whitty, Power y Halpin, 1999, p. 17). Estos autores observan una tendencia en la década de los ochenta a desmantelar el centralismo burocrático a través de la introducción de dos elementos básicos: la elección de los padres y el reforzamiento de la participación de la comunidad en las escuelas (mayor autonomía escolar). Estos dos elementos se presentan como los dispositivos necesarios para vehicular la descentralización de la educación. Entienden los autores que, lejos de cualquier neutralidad técnica, ambos dispositivos incluyen rasgos propios del mercado sirviendo, por lo tanto, como mecanismos de privatización.

En este escenario, el rol del Estado se reconfigura de dos maneras. Por una parte, deja de ser un agente de la educación para convertirse en "un proveedor de 
recursos y financieros y un comprador de servicios" (Puelles, 2005, p. 232). Por otra parte, en el modelo de cuasi mercado, suele actuar como un "Estado evaluador", lo que significa que aunque se delegue mayores responsabilidades a los centros, no están en absoluto fuera del control estatal, ya que el Estado fija los objetivos de las escuelas (Whitty, Power y Halpin, 1999). Obsérvese que esta conversión en "Estado evaluador" es lo que previamente se ha catalogado como regulación postburocrática (inscrita como mecanismos de privatización endógena). En última instancia no se trata, por lo tanto, de estrategias de descentralización, sino de un hibridismo entre centralización y descentralización, siempre cruzado por mecanismos diversos de mercado.

Para Roger Dale, la gobernabilidad del sistema educativo es el conjunto de procedimientos para conseguir los objetivos deseados - objetivos marcados por el mandato educativo y limitados por la capacidad del Estado - (Tarabini y Bonal, 2011). Cabe considerar que los dispositivos que introducen los cuasi mercados constituyen los procedimientos de la gobernabilidad en el Estado competitivo. Previamente se ha aludido a la reducción de la capacidad del Estado en un entorno de globalización neoliberal para actuar de manera alternativa. A modo de ejemplo, Tarabini y Bonal (2011) recuerdan la recomendación la Unión Europea a los Estados miembros para llevar a cabo estrategias de descentralización en materia educativa, tratando el asunto como si fuera meramente técnico. En términos similares, la OCDE recomienda la introducción de evaluaciones estandarizadas y estrategias de rendición de cuentas (OCDE, 2013). Haciéndose eco de estas propuestas, la reforma de la LOMCE introduce más evaluaciones externas (profundizando en una línea ya iniciada por la Ley Orgánica de Educación de 2006), fortalecimiento de la figura del director e incluyendo mecanismos de rendición de cuentas asociados a protocolos de calidad. Estos elementos se articulan para dotar de mayor autonomía a los centros escolares y así favorecer la competitividad del sistema educativo.

Las políticas públicas siempre son resignificadas por los sujetos a los que involucran (Ramírez,2010). Desde esta premisa, la investigación educativa ya se ha ocupado de cómo las representaciones y las prácticas educativas son reconfiguradas en el modelo de cuasi mercado, afectando a las identidades de los sujetos y de las instituciones escolares (Ball, 2013; Dubet, 2007; Jódar y Gómez, 2007; Luengo y Saura, 2013).

Previamente ya se ha apuntado el modo en que estos dispositivos afectan a la identidad del docente. Stephen Ball (2003) habla de un docente performativo, cuyo profesionalismo queda fuertemente reconfigurado en atención a la organización gerencialista. El nuevo profesional docente no se caracteriza ya por el pensamiento crítico en el marco de sus tareas, es decir, por una especial relación ética con su trabajo. Antes bien, la cultura gerencialista lo caracteriza como un mero actor que sigue el guion escrito por la dirección escolar y la administración educativa, de tal suerte que solamente debe ceñirse a los códigos éticos del gerencialismo. Esto genera sentimientos de inseguridad y culpa en muchos profesores al existir "una potencial fisura entre el juicio del propio profesor sobre, de un lado, lo que significa una buena práctica y las necesidades de los estudiantes y, de otro, el rigor de la performance" (Ball, 2013, p. 107). Las observaciones de Louise Poulson (1998) caminan en un sentido similar, confirmando que los mecanismos de rendición de cuentas contri- 
buyen a crear una cultura de la vigilancia que afecta sobre el trabajo y la identidad profesional del docente. En España, investigaciones recientes avalan la remodelación de la identidad del profesor en esta dirección (Luengo y Saura, 2013).

En su trabajo, Biesta (2004) cuestiona el potencial democrático de la retórica de la rendición de cuentas (accountability) en educación cuando se vincula a la elección de centro de por parte de las familias. Explica el autor cómo este discurso recodifica las relaciones entre el Estado y las familias en términos económicos más que políticos o sociales. Las familias son vistas por parte de las escuelas como clientes que se limitan a exigir calidad del producto educacional, lo que provoca que la institución escolar se vea obligada a elaborar una fabricación de sí misma acorde con las supuestas exigencias de los padres/consumidores (Ball, 2013). En este escenario, la noción “ciudadanía” se vacía de contenido político (Biesta, 2004). La elección de centro es el dispositivo clave para crear esta identidad clientelar, ya que la libertad de elección es uno de los principios básicos de mercado. Para que los consumidores puedan elegir, es necesario que se proporcione información al mercado, y las evaluaciones estandarizadas, junto con la publicación de los resultados, es el elemento que tiene por objetivo proporcionar esa información. La introducción de libertad de elección parte de la creencia en la autorregulación del mercado, lo que contribuirá a elevar la calidad educativa. Esto, sin embargo, no es avalado por la realidad (Corvalán y Román, 2012).

La identidad del alumnado también es recodificada. Sus representaciones y prácticas se ven más influidas por el modo en que todos estos dispositivos de cuasi mercado colaboran conjuntamente reorientando el sentido de la educación. Actualmente, el alumnado observa la educación principalmente como una inversión de cara a un mercado laboral precario e incierto. El término "empleabilidad", incluido en la estrategia de Lisboa para opacar la crisis de empleo, coloca en los estudiantes la obligación de invertir en sí mismos, orientando su educación hacia las necesidades laborales (Nóvoa, 2010). A este respecto, Rizvi y Lingard (2013) destacan la creciente percepción de que la educación es una continua autocapitización de uno mismo. Se forma así una nueva subjetividad en el estudiante: "el sujeto autorresponsable, siempre en curso y empresario de sî” (Jódar y Gómez, 2007, p. 383).

Algunas instituciones participan de esta transformación de las identidades. Es el caso de la OCDE (OCDE, 2013) o la Unión Europea, que parecen apoyar políticas del modelo de cuasi mercado. En la misma línea se sitúa la OMC que, en el Acuerdo General sobre el Comercio de Servicios, sitúa a "la educación como servicio comercializable extraordinariamente atractivo para el capital”(Bonal, 2009, p. 656).

Sin embargo, este modelo de cuasi mercado ha sido ampliamente rechazado. Ball y Olmedo (2013) han prestado atención a los modos en que los profesores y profesoras, a título individual, resisten a estas tecnologías de gubernamentalidad neoliberal dentro de la escuela: cuestionan la prioridad que se da a los resultados sobre los procesos, a los procedimientos sobre las ideas, a los números sobre las experiencias... Se oponen a convertirse en docentes performativos. Desde este punto de vista foucaultiano, se pone el foco de atención en la subjetividad como lugar desde donde pensar la resistencia y la transgresión diaria. Este grupo de docentes "pugna por producir identidad y significado dentro de las limitaciones estructurales 
y discursivas de su práctica diaria”2 (Ball y Olmedo, 2013, p. 91).En otras palabras, la concepción del profesionalismo docente se convierte en terreno de disputa.

También las familias de estudiantes se han mostrado opuestas a estas políticas de mercantilización. En España, cabe mencionar el boicot de muchas asociaciones de madres y padres a las evaluaciones externas, sobre todo en la Comunidad de Madrid, donde la Consejería de Educación Publica anualmente un ranking con los resultados de los centros. La Federación de la Comunidad de Madrid de Asociaciones de madres y padres Giner de los Ríos ha llamado anualmente al boicot de estas pruebas pidiendo que ese día las familias no lleven a sus hijas e hijos a la escuela (FAPA Giner de los Ríos, 2014). En el último curso, y en rechazo a las evaluaciones implementadas por la LOMCE, también en Cataluña muchas familias boicotearon las evaluación de tercero de primaria (Baquero y Álvarez, 2015).

Aglutinando tanto a profesorado como a familias, el movimiento de la marea verde en defensa de la escuela pública ha cobrado protagonismo a nivel estatal. Recientemente las Mareas por la Educación Pública han publicado una carta (2015) donde expresan su postura contra la privatización de la educación y contra las evaluaciones externas que contribuyen a su mercantilización. De la misma manera, piden un modelo de organización escolar más democrático que no emule el modelo gerencialista. Como expresan en el texto, conciben la educación como un "derecho de carácter universal que debe pertenecer y acoger a toda la población sin distinción de origen, condiciones o circunstancias" (Mareas por la Educación Pública, 2015, p. 3).

\section{CONCLUSIÓN: EL CAMPO DE LA EDUCACIÓN COMO ESPACIO DE LUCHA SIMBÓLICA}

Para Bourdieu, los habitus son las estructuras cognitivas a través de las que los individuos aprehenden el mundo social. Estas estructuras cognitivas son el resultado de la interiorización del mundo social. Desde esta premisa, cuando los sujetos interiorizan una organización educativa de acuerdo con los dispositivos de cuasi mercado, estos pueden ser naturalizados (asumidos acríticamente) por los sujetos que, por lo tanto, transforman su identidad en adaptación a ese mundo social. "A través de los habitus, tenemos un mundo de sentido común, un mundo social que parece evidente"(Bourdieu, 2000, p. 135). Las luchas simbólicas son disputas por el control de esos habitus, por monopolizar el "sentido común". Son disputas que se vehiculan a través de discursos o teorías. Pero es importante tener en consideración que para que un discurso sea tomado por legítimo tiene que tener algún fundamento en la realidad, consagrando así la relación dialéctica entre discurso y realidad. Sobre este punto es importante observar que el neoliberalismo en tanto que discurso fuerte (Bourdieu, 1998), es él mismo quien fabrica ese fundamento en la realidad. En otras palabras, si el mundo es competitivo en términos económicos, es porque instancias internacionales y supranacionales actúan haciéndolo competitivo. Sin embargo, esto

$\overline{2 \text { Traducción propia. }}$ 
es una verdad a medias. Las grandes transnacionales, cada vez más independizadas de los Estados nacionales, no están tan sometidas a las leyes del libre mercado que propugnan, como los pequeños empresarios y los empleados que sí experimentan la competitividad del mundo económica. Esto se explica porque el libre mercado neoliberal es un discurso de "doble filo: proteccionismo y subsidio público para los ricos, disciplina de mercado para los pobres" (Chomsky y Dieterich, 1996, p. 32).

El capital simbólico es reconocido como tal cuando las categorías de percepción que impone en su discurso son legitimadas por otros sujetos y, por lo tanto, las aplican a sus estructuras cognitivas, sus habitus. A este respecto, la reforma educativa planteada por la LOMCE es legitimada por aquellas personas que reconocen los mismos principios de visión y división que plantea el entramado neoliberal. No obstante, como se mencionó en la introducción, amplios sectores académicos y sociales (Bernal y Lorenzo, 2012; Bolívar, 2013; Escudero, 2013; Monarca, 2012b), como la marea verde, observan la educación desde otras categorías de percepción, propias del Estado de Bienestar y el lenguaje de los derechos, donde la educación es un derecho humano y no un servicio comercializable.

Ocurre que la virulencia de las reformas neoliberales hace surgir discursos de resistencia que se oponen con firmeza a ellas. Estos discursos deben ser observados como "expresiones de identidad y ciudadanía" (Janoschka, 2011), donde el concepto de "ciudadanía" se forja desde habitus creados en el escenario del Estado de bienestar. Otros actores no expresan identidades de resistencia, sino que resignifican sus prácticas y representación adaptándose a los nuevos dispositivos de cuasi mercado. Ello, sin embargo, no siempre significa un abandono total de los habitus propios del Estado de bienestar. Así, algunas investigaciones de corte cualitativo reflejan la adaptación de muchos profesores a los cambios, pero también la desmotivación que estos cambios despiertan en ellos y el desacuerdo profundo que a veces sienten (Ball, 2013; Luengo y Saura, 2013).

Cabe confirmar en el momento actual la existencia de una disputa simbólica por el modelo social y educativo. En esta disputa participan, entre otros posibles actores, valedores de las políticas de cuasi mercado y los sectores sociales que se resisten a ellas. Estos últimos se articulan como actores políticos a través de movimientos sociales, pero también están presentes en la literatura académica, partidos e instituciones políticas, todos ellos con diversidad de matices y tonalidades. Estas expresiones sociales de identidad luchan por obtener "el monopolio del sentido común", por configurar los habitus de los sujetos. No obstante, en este escenario de sociedad performativa, el poder simbólico está distribuido de manera desequilibrada y a favor de los poderes económicos.

\section{REFERENCIAS}

Austin, J. L. Cómo hacer cosas con palabras. Barcelona: Paidós, 1971.

Avellaneda, S. Política y evaluación de políticas públicas. El carácter político de la evaluación. Boletín Informativo de Trabajo Social, Cuenca: Escuela Universitaria de Trabajo social, n. 16, dic. 2011. Disponible en: <http://www.uclm.es/bits/sumario/ articulo.asp?a=15-06>. Acceso en: 13 nov. 2014. 
BAll, S. Profesionalismo, gerencialismo y performativiad. Educación y Pedagogía, Antioquía: Facultad de Educación de la Universidad de Antioquía, v. 15, n. 37, p. 87-104, mayo/ago. 2003.

. Performatividad y fabricaciones en la economía educacional: rumbo a una sociedad performativa. Pedagogía y Saberes, Bogotá: Universidad Pedagógica Nacional, n. 38, p. 103-113, enero/jun. 2013.

Ball, S.; Olmedo, A. Care of the self, resistance and subjectivity under neoliberal governmentalities. Critical Studies in Education, London: University of London, v. 54, n. 1, p. 85-96, 2013.

Ball, S.; Youdell, D. Privatización encubierta de la educación pública. Utopias Nuestra Bandera, Madrid: Partido Comunista Español, v. II, n. 220, p. 57-92, 2009.

Baquero, C.; Álvarez, P. Colegios catalanes boicotean la primera gran evaluación de Wert. El País, Madrid: Grupo Prisa, 5 mayo 2015. Disponible en: <http://ccaa. elpais.com/ccaa/2015/05/04/catalunya/1430737730_205810.html>. Acceso en: 5 enero 2016.

Barrenechea, I. Evaluaciones estandarizadas: seis reflexiones críticas. Archivos Analíticos de Políticas Educativas, Arizona: Arizona State University, v. 18, n. 8, p. 1-27, 2010.

Basterra, J. E1 82\% de las empresas del Ibex acude a paraísos fiscales. Diario Gara, San Sebastián: Euskal Komunikabideen, Feb. 2011. Disponible en: < http://gara.naiz. eus/paperezkoa/20110215/248556/es/E1-82-empresas-Ibex-acude-paraisos-fiscales >. Acceso: 10 dic. 2014.

Bauman, Z. Los retos de la educación en la modernidad líquida. Madrid: Gedisa, 2005.

Bernal, J. L.; Lorenzo, J. La privatización de la educación pública. Una tendencia en España. Un camino encubierto hacia la desigualdad. Profesorado - Revista de currículum y formación del profesorado, Granada: Universidad de Granada, v. 16, n. 3, p. 81-109, 2012.

Biesta, G. Education, accountability and the ethical demand: can the democratic potential of accountability be regained? Educational Theory, Illinois: University of Illinois, v. 54, n. 3, p. 233-250, ago./oct. 2004.

Bolívar, A. La autonomía de los centros educativos en España. CEE Participación Educativa, Madrid: Consejo Escolar de Estado, n. 13, p. 8-25, marzo 2010.

- ¿Cómo incide la LOMCE en la organización de los centros? Fórum Aragón, Aragón: Forum Europeo de Administraciones de Educación, n. 7, p. 9-12, 2013.

Bonal, X. La educación en tiempos de globalización: ¿quién se beneficia? Educação E̋ Sociedade, Campinas: CEDES, v. 30, n. 108, p. 653-671, out. 2009.

Bourdieu, P. The essence of neoliberalism. Le Monde Diplomatique, París: Le Monde. 1998. Disponible en: <http://mondediplo.com/1998/12/08bourdieu $\geq$. Acceso en: 10 dic. 2014.

. Cosas dichas. Barcelona: Gedisa, 2000.

Bridgman, P. W. The logic of modern physics. Nueva York: Macmillan. 1928. 
CARvalHo, L.M. Governando a educação pelo espelho do perito: uma análise do PISA como instrumento de regulação. Educação E' Sociedade, Campinas: CEDES, v. 30, n. 109, p. 1.009-1.036, out. 2009.

CERny, P. Paradoxes of the competition state: The dynamics of political globalization. Government and Opposition, Cambridge: Cambridge University Press, v. 32, n. 2, p. 251-274, abr./jun. 1997.

Charlton, B. G. Audit, accountability, quality and all that: the growth of managerial technologies in UK universities. In: Prickett, S.; Erskine-Hill, P. (Org.). Education! education! education! Managerial ethics and the law of unintended consequences, Thorverton: Imprint Academic, 2002. p. 13-28.

Сномкку, N. La (des)educación. Barcelona: Crítica, 2007.

Chomsкy, N.; Dieterich, H. La aldea global. Tafalla: Txalaparta, 1996.

UNA MOSCA EN una botella de Coca-Cola. Producción de CMI/OMAL-Paz don Dignidad; Dirección: Javier Couso. España: 2014.

Cortes Generales de España. Diario de Sesiones de Sesiones del Congreso de los Diputados, Madrid: Cortes Generales, legislatura X, n. 197,2014. Disponible en: <http:// www.congreso.es/public_oficiales/L10/CONG/DS/PL/DSCD-10-PL-197.PDF >. Acceso en: 10 dic. 2014.

Corvalán,J.; Román, M. La permanencia de escuelas de bajo rendimiento crónico en el cuasi mercado educativo chileno. Revista Uruguaya de Ciencia Politica, Montevideo: Instituto de Ciencia Política, v. 21, n. 1, p. 43-64, enero/jun. 2012.

Dale, R. The State and education policy. Milton Keynes: Open University Press, 1989.

Deleuze, G. Post-scriptum sobre las sociedades de control. Polis, Santiago: CISPO, v. 5, n. 13, 2006. Disponible en: <http://polis.revues.org/5509>. Acceso en: 16 enero 2015. Díaz-Palacios, J. A. Calidad educativa: un análisis sobre la acomodación de los sistemas de gestión de la calidad empresarial a la valoración en educación. Tendencias Pedagógicas, Madrid: Departamento de Didáctica y Teoría de la Educación UAM, n. 21, p. 177-194, enero/jun. 2013.

Díaz-Villa, M. Los discursos sobre la flexibilidad y las competencias en la educación superior. Pedagogía y Saberes, Bogotá: Universidad Pedagógica Nacional, n. 35, p. 9-24, jul./dic. 2011.

Díez-Gutiérrez, E. J. La globalización neoliberal y sus repercusiones en educación. Revista Electrónica Interuniversitaria de Formación del Profesorado, Zaragoza: AUFOP, v. 13, n. 2, p. 23-38, abr./jun. 2010.

Díez-Gutiérrez, E. J.; Guamán, A. Educación pública: de tod@s para tod@s: Las claves de la marea verde. Madrid, Bomarzo, 2013.

Dubet, F. El declive y las mutaciones de la institución. Revista de Antropología Social, Madrid: UCM, n. 16, p. 39-66, 2007.

Escudero, J. M. Nos va a caer como una losa. El País, Madrid: Grupo Prisa, 20 enero 2013. Disponible en: <http://sociedad.elpais.com/sociedad/2013/01/17/ actualidad/1358441982_492947.html $\geq$ Acceso en: 15 enero 2015. 
Fairclough, N. Representaciones del cambio en el discurso neoliberal. Cuaderno de Relaciones Laborales, v. 16, p. 13-35, enero/jun. 2000.

FAPA Giner de Los Ríos. Nota de prensa de la FAPA en la que muestra nuevamente su rechazo a la prueba CDI de sexto de educación primaria. Madrid: FAPA, 11 mayo 2014. Disponible en: <http://www.fapaginerdelosrios.org/actualidad/detalles/462/3/ $\geq$. Acceso en: 5 enero 2016.

Fraser, N. From discipline to flexibilization. Constellations, Nueva York: Columbia University, v. 10, n. 2, p. 160-171, 2003.

Giddens, A. La tercera vía: la renovación de la socialdemocracia. Madrid: Taurus, 1999 Gurría, Á. "Editorial. Fifty years of change in education”.In: OCDE - Organization for Economic Cooperation and Development (Org.). Education at a glance 2011: OCDE indicators. París: OCDE Publishing, 2011. p. 13-20. Disponible en: <http:// www.oecd.org/education/skills-beyond-school/48631582.pdf>. Acceso en: 10 dic. 2014. Hargreaves, A. Profesorado, cultura y postmodernidad: cambian los tiempos, cambia el profesorado. Madrid: Morata, 1996.

Harver, D. La condición de la posmodernidad. Buenos Aires: Amorrortu, 1990.

.El "nuevo" imperialismo: acumulación por desposesión. Socialist Register, v. 40, p. 99-129, 2004a. Disponible en: <http://socialistregister.com/index.php/srv/issue/ archive\#.VLldjEeG_Ow>. Acceso en: 15 enero 2015.

. El nuevo imperialismo. Madrid: Akal, 2004b.

Herman, E. S.; Сhomsкy, N. Manufacturing consent: the political economy of the mass media. New York: Pantheon Books, 2002.

Hernández,J. Los lobbies financieros: tentáculos de poder.Madrid: Clave Intelectual, 2013. ÍñIguEZ, L. El lenguaje en las ciencias sociales: Fundamentos, conceptos y modelos. In: .(Org.).Análisis del discurso: manual para las ciencias sociales. Barcelona: UOC, 2003.

JanoschкA, M. Geografías urbanas en la era del neoliberalismo. Una conceptualización de la resistencia local a través de la participación y la ciudadanía urbana. Investigación Geograficas, México, DF: Instituto de Geografia UNAM, n. 76, p. 118-132, sept./dic. 2011. JóDAR, F.; GómEz, L. Educación posdisciplinaria, formación de nuevas subjetividades y gubernamentalidad neoliberal. Revista Mexicana de Investigaciones educativas, México, DF: Consejo Mexicano de Investigación Educativa, v. 12, n. 32, p. 381-404, abr./jun. 2007.

Kamens, D. H. Globalization and the emergence of an audit culture: PISA and the search for "best practices" and magic bullets". In: Meyer, H.-D.; Benavot, A. (Orgs.). PISA power and policy: the emergence of global educational governance. Oxford: Symposium Books, 2013.

Laval, C.; Dardot, P. Común. Ensayo sobre la revolución en siglo XXI. Barcelona: Gedisa, 2015.

Luengo, J.; Saura, G. Mecanismos endógenos de privatización encubierta en la escuela pública. Políticas educativas de gestión de resultados y rendición de cuentas en Andalucía. Profesorado - Revista de currículum y formación del profesorado, Granada: FORCE, v. 16, n. 3, p. 133-148, sept./dic. 2012. 
Luengo, J.; Saura, G. La performatividad en la educación. La construcción del nuevo docente performativo y el nuevo gestor performativo. Revista Iberoamericana sobre Calidad, Eficacia y Cambio en Educación, RINACE, v. 11, n. 3, p. 139-153, jul./sept. 2013. Luzón, A.; Torres, M. La presencia de PISA en la literatura científica y su tratamiento en la prensa internacional”. Profesorado, Granada: FORCE, v. 17, n. 2, p. 193-224, mayo/ago. 2013.

Lyotard, J. F. La condición postmoderna. Madrid: Cátedra, 1987.

Marcuse, H. El hombre unidimensional. Barcelona: Planeta, 1993.

Mareas por la Educación Pública. Carta por la educación pública. 2015. Disponible en: <http://mareasporlaeducacionpublica.blogspot.com.es/2015/09/carta-por-laeducacion-publica-mareas.html $\geq$. Acceso en: 5 enero 2016.

Merchán, F.J. La introducción en España de la política educativa basada en la gestión empresarial de la escuela: El caso de Andalucía. Archivos Analíticos de Políticas Educativas, Arizona: Arizona State University, v. 20, n. 32, p. 1-28, oct. 2012.

Monarca, H. La influencia de los sistemas nacionales de evaluación en el desarrollo del currículo. Perfiles Educativos, México, DF: Instituto de Investigaciones sobre la Universidad y la Educación, v. XIV, n. 135, p. 164-176, 2012a.

. La nueva ley orgánica para la mejora de la calidad educativa. La restauración del discurso conservador. Tendencias Pedagógicas, Madrid: Universidad Autónoma de Madrid, v. 20, p. 107-121, enero/mar. 2012b.

Monarca, H.; Fernández-González, N.; Sandoval, M. Reconfiguración de los sentidos sobre la educación en España a partir de la nueva ley de educación (LOMCE). In: Monarca, H. (Coord.). Evaluaciones externas: mecanismos para la configuración de representaciones y prácticas en educación. Buenos Aires: Miño y Dávila, 2015.

NóvoA, A. La construcción de un espacio educativo europeo: gobernando a través de los datos y la comparación. Revista de Educación Comparada, Madrid: UNED, n. 16, p. 23-41, jul./dic. 2010.

OCDE - Organization for Economic Cooperation and Development. PISA 2012 results: what makes schools successful? Resources, policies and practices (v. IV). París: OECD Publishing, 2013. Disponible en: <http://www.oecd.org/pisa/keyfindings/ pisa-2012-results-volume-IV.pdf>. Acceso en: 10 dic. 2014.

Pedró, F. Deconstruyendo los puentes de PISA: del análisis de resultados a la prescripción política. Revista Española de Educación Comparada, Madrid: UNED, n. 19, p. 139-172, enero/jun. 2012.

Pereyra, M. Á.; Luzón, A.; Torres, M. PISA, un nuevo escenario en la política educativa mundial. Organización y Gestión Educativa, Madrid: Ciss Praxis, v. 18, n. 6, p. 12-17, nov./dic. 2010.

Pérez, C.; Salinas, J. Cuasimercados en el ámbito educativo: una aproximación a la experiencia británica. Revista Gestión y Análisis de Políticas Públicas, Madrid: INAP, n. 16, p. 145-152, jul./dic. 1999. 
Pini, M. Análisis crítico del discurso: políticas educativas en España en el marco de la Unión Europea. Revista de la Asociación de Sociología de la Educación, Madrid: ASE, v. 3, n. 1, p. 105-127, sept./dic. 2010.

Pongratz, L. La reforma educativa como estrategia gubernamental. ProfesoradoRevista de curriculum y formación del profesorado, Granada: FORCE, v. 17, n. 2, p. 141-152, mayo/ago. 2013.

Poulson, L. Accountability, teacher professionalism and education reform in England. Teacher Development, London: Routledge, v. 2, n. 3, p. 419-443, abr./jun. 1998.

Puelles, M. La influencia de la nueva derecha inglesa en la política educativa española. Historia de la Educación: Revista Interuniversitaria, Salamanca: Universidad de Salamanca, n. 24, p. 229-253, 2005.

Ramírez, M. C. Antropología de la política pública. Antípoda, Bogotá: Universidad de los Andes, n. 10, p. 13-17, enero/jun. 2010.

Rizvi, F.; Lingard, B. Politicas educativas en un mundo globalizado. Madrid: Morata, 2013. Tarabini, A.; Bonal, X. Globalización y política educativa: los mecanismos como método de estudio. Revista de Educación, Madrid: Ministerio de Educación, Ciencia y Deporte de España, n. 355, p. 235-255, mayo/ago. 2011.

Tröhler, D. Armonizar la el globo educativo. Política mundial, rasgos culturales y los desafíos investigación educativa. Profesorado - Revista de currículum y formación del profesorado, Granada: FORCE; v. 13, n. 2, p. 11-14, mayo/ago. 2009.

Whitty, G.; Power, S.; Halpin, D. La escuela, el estado y el mercado. Madrid: Morata, 1999.

\section{SOBRE LA AUTORA}

Noelia Fernandez Gonzalez es doctora en educación por la Universidad Autónoma de Madrid (España). Profesora de la misma institución. E-mail:nfg.fernandeznoelia@gmail.com

Recebido em 21 de abril de 2015 Aprovado em 1 de fevereiro de 2016 